\title{
Factors affecting conception rates in cattle following embryo transfer
}

M.N. Ongubo ${ }^{1,2}$, H.A. Rachuonyo ${ }^{2}$, F.N. Lusweti ${ }^{1}$, D.K. Kios ${ }^{2}$, J.K. Kitilit ${ }^{2}$, K. Musee ${ }^{3}$, W.K. Tonui ${ }^{3}$, I.K. Lokwaleput ${ }^{1}$ and G.O. Oliech ${ }^{2}$

${ }^{1}$ Kenya Agricultural Research Institute, P. O. Box 450-30200, Kitale, Kenya

${ }^{2}$ University of Eldoret, P. O. Box 1125-30100, Eldorete, Kenya

${ }^{3}$ Agricultural Development Corporation, P. O. Box 917-30200, Kitale, Kenya

Author for correspondence: ongubomary@yahoo.com

\begin{abstract}
Embryo Transfer Technology (ETT) plays an important role in improving productivity of dairy cattle (Bos indicus). Embryo Transfer Technology allows top quality female livestock to improve a herd or flock in much the same way that artificial insemination has allowed greater use of superior sires. The technology hastens genetic enhancement by virtue of its capacity to reduce generation interval and is also useful in progeny testing programmes. A retrospective study analysed conception rates data collected over a period of six years, from 2007 to 2012. A total of 115 embryos had been transferred during that period. The factors affecting conception rates (CR) included embryo developmental stage, deposit site and stage of recipient in days after estrus. The deposit site had a significant effect on $C R\left(\chi^{2}=0.27395 ; p<0.05\right)$. The quality and stage of the embryo development influenced the CR. Generally, CR reduced as the growth of the embryo. Days after estrus also significantly affected the CR, whereby transfer on day 8 resulted in more conceptions in recipient animals. Even though ETT has several benefits and requires consistent promotion, challenges such as lack of trained personnel and equipment for ovulation and packaging of embryos at the farm site need to be addressed.
\end{abstract}

Key words: Artificial insemination, Bos indicus, conception rate

\section{Introduction}

Developing countries have nearly two thirds of the world livestock population, but produce only about a quarter to a third of the world's meat, and a fifth of the milk (Rege, 2009). In East Africa and Kenya in particular, the dairy industry is the most advanced of the livestock sub-sectors. The livestock sector in Kenya contributes $10-12 \%$ of the GDP, which represents $47 \%$ of the Agricultural GDP (Mwangi and Omore, 2004; Kabubo-Mariara, 2009; Kios et al., 2011). Dairy farming 
contributes nearly half of this through milk production, sale of breeding stock, among others.

New technologies can help achieve increased productivity, but need to be transferred to producers to cause impact (Ehui and Shapiro, 2009; Yang and Honaramooz, 2010). One such technology is whereby one high quality cow could be made to produce up to 32 embryos per year compared to the conventional method of breeding where the farmer has to wait for twelve months for a calf that could be either male or female (Muchemi, 2011). The reproductive potential of a female newborn calf is enormous and is estimated at 150,000 ova per cow (Glenn, 2004). This reproductive potential has largely been underutilised.

Naturally, a cow produces about 8 to 10 calves in her lifetime. But with embryo transfer, it is possible to get 32 embryos per cow per year. Embryo transfer is a technique that can greatly increase the number of offspring that a genetically superior cow can produce (Glenn, 2004; Steel and Hasler, 2004).

Under conventional ways, the generation interval ranges between 6 and 7 years, but with MOET, it can be reduced by almost half. It is also useful in progeny testing programmes, due to reduction in generation interval (Hasler, 2012). Embryo transfer techniques (ETT) are very effective for the propagation of superior genes, although factors such as lactation status of recipient animals; time of embryo recovery after insemination; site of embryo placement in recipient's uterus; embryo size; quality and stage of development, all influence implantation and overall conception rate (Peterson and Lee, 2003; Lamb, 2012; Mapletoft et al., 2012).
Most small scale farmers have no breeding objectives and may use artificial insemination or natural service to sustain milk production and calf crop. The aim is for the cow to produce milk after calving and not the quality of heifer produced. To sustain demand for milk which is ever on the rise, a few of these farmers turn to large scale breeders for quality breeding stock. Attempts to bridge this gap with newer technologies, including MOET, Artificial Insemination (AI) and invitro Embryo Production (IVEP) has not been successful. This has led to high costs of production of heifers, thus discouraging adoption of such high value technologies and as such. The objective of this study was to determine factors affecting the conception rate following embryo transfer in indigenous cattle (Bos indicus) in Kenya.

\section{Materials and methods}

The study was done basing on primary and secondary data on Multiple Ovulation and Embryo Transfer (MOET) at the Agricultural Development Corporation (ADC), Namandala farm in Trans-Nzoia County in the North Rift region of Kenya. The farm is situated $10 \mathrm{Km}$ from Kitale town on the Kitale-Mt Elgon road, at an altitude of 1800-1900 m above sea level. Temperatures range from 10 to $27^{\circ} \mathrm{C}$, with an annual bimodal rainfall of 1000$1200 \mathrm{~mm}$ per year, occurring mostly in April to August and October to November. This study examined data collected over a period of six years (2007 - 2012) from the farm. The Corporation, being the custodian of the National Cattle Stud Herds, has taken the lead in adoption of new technologies particularly MOET. 
Data were stored in two different Databases (DB); namely, (i) DB1 contained data regarding fresh embryos $(n=108)$, frozen embryos $(n=7)$ and stages of embryo transfer; and (ii) DB2 contained data on transfers $(n=115)$, the deposit site and stage of the recipient animal in days after estrus.

\section{Embryo evaluation}

The embryos collected by uterine flushing were classified according to the rules of the International Embryos Transfer Society (IETS) of Robertson and Nelson

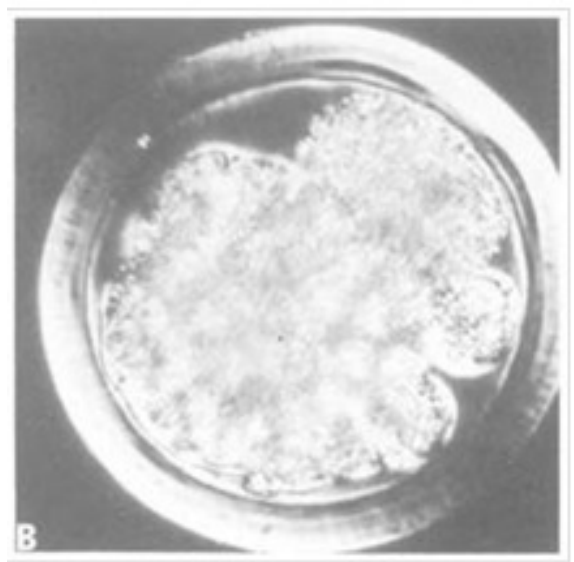

(a)

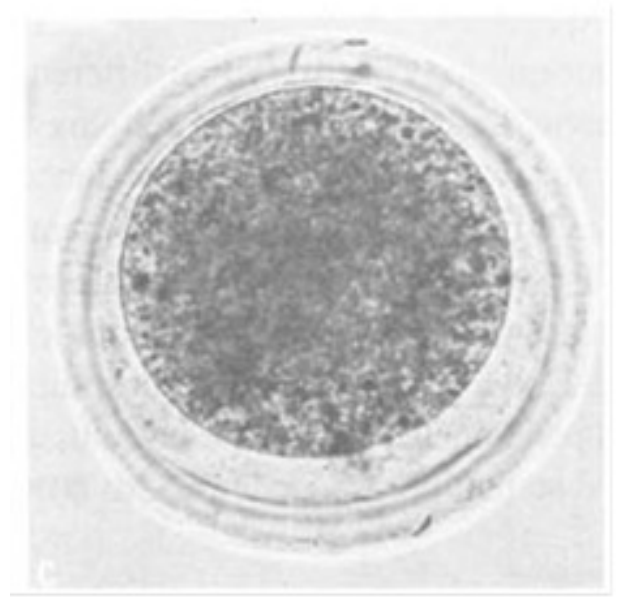

(1998). The embryos were classified into five developmental stages, viz:

i. A - Morula,

ii. B - Early blastocyst,

iii. C - Full blastocyst,

iv. D - Expanded blastocyst, and

v. E - Hatched blastocysts

Only A, B, C and D were considered as transferable. Stage $\mathrm{E}$ is not transferable because it is difficult to trace due to lost zona pellucida.

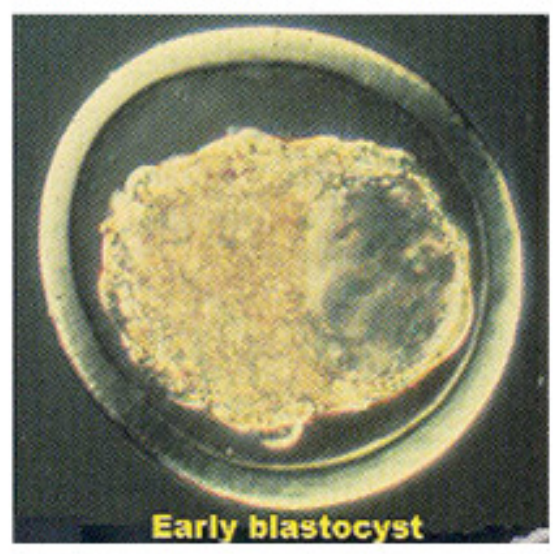

(b)

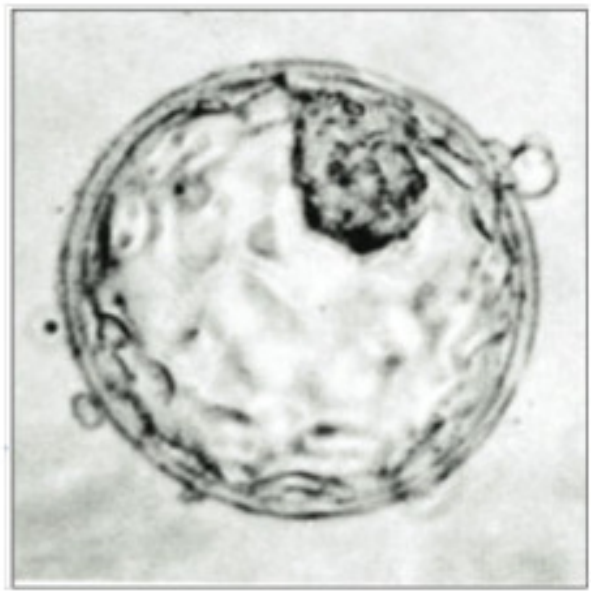

Figure 1. (a) Morula, (b) Early Blastocyst, (c) Full Blastocyst, and (d) Expanded Blastocyst. 


\section{Recipient synchronisation}

To maximise embryo survival in recipients, the cows require synchronisation of estrus cycle. The synchronisation protocol used is shown in Table 1.

\section{Embryo transfer}

Selection of embryo transfer recipients was based on breeding parameters and using the following criteria; cows that are reproductively sound, those that exhibit calving ease, have good milking and mothering ability. Their estrus was synchronised.

Before the transfer of embryos, the recipient cows were palpated for presence of the corpus luteum (CL). An epidural injection of 5-7 $\mathrm{ml}$ of Lidocaine hydrochloride $2 \%$ was administered for smooth handling of the genitalia. The ovaries of the recipient animal were palpated rectally to determine the ovary that ovulated. An embryo was then loaded into $25 \mathrm{ml}$ insemination straw and put in transfer gun. The transfer gun/ insemination rod was carefully passed through the cervix. The embryo was then deposited in the uterine horn epsilateral to the side of the CL. All transfers were performed non-surgically, a technique that was adapted from a trainer named Dr. David Steel at the farm in the late 1990s.

\section{Data collection and analysis}

Data Base (DB) 1 was analysed for data regarding fresh embryos $(n=108)$, frozen embryos $(n=7)$ and the stages of embryo transfer. DB2 was analysed for transfers $(n=115)$, deposit site and the stage of recipient in days post-estrus. In the DB2, effects of the following parameters on conception rate were investigated: embryo stage of development, stage of the recipient animal (days after estrus) and the deposit site.

The data were analysed for correlations between variables. Simple descriptive statistics was used to get means and proportions. In each $\mathrm{DB}$, the variables were tested for the significant relations. The regression model was used to study the effect of factors on the conception rate. The model was specified as:

Logit regression model

$$
\begin{aligned}
& Y_{i}=\operatorname{Ln}\left(P_{x i} /\left(1-P_{x j}\right)=\beta_{0}+\beta_{1} X_{1 j}\right. \\
& +\beta_{2} X_{2 j}+\beta_{3} X_{3 i}+e
\end{aligned}
$$

Where:

$Y_{i}=1$ if the $\mathrm{i}^{\text {th }}$ recipient conceives $=0$ otherwise;

Table 1. Recipient protocol synchronises

\begin{tabular}{lll}
\hline Days in sequence & Time of day & Activity \\
\hline 1 & $8.00-10.00 \mathrm{AM}$ & Inject 20 ml multivitamin \\
7 & $8.00-10.00 \mathrm{AM}$ & Insert CIDR device+2 mls ciderol \\
12 & $8.00-10.00 \mathrm{AM}$ & Inject Estrumate \\
14 & $8.00-10.00 \mathrm{AM}$ & Inject Estrumate \\
15 & $8.00-10.00 \mathrm{AM}$ & Remove CIDR device \\
16 & $8.00-10.00 \mathrm{AM}$ & Observe heat \\
24 & $8.00 \mathrm{AM}-5.00 \mathrm{PM}$ & Transfer \\
\hline
\end{tabular}

$\mathrm{CIDR}=($ Controlled Internal Drug Release device $)$ 
$P(x i)$ is success odds ratio (probability of a cow conceiving);

$i=1 \ldots . \mathrm{n}$;

$\beta_{o}=$ Intercept (constant term);

$\beta_{l}=1-3$ regression coefficient for the $\mathrm{i}^{\text {th }}$ factor;

$X_{1 i}=$ Embryo stage of development;

$X_{2 i}=$ Deposit site;

$X_{3 i}=$ Days after estrus for $\mathrm{i}^{\text {th }}$ cow; and

$e=$ error term

\section{Results and discussion}

Data revealed that in 2007 conception rates stood at $25 \%$, but increased to 34.4 and $36.8 \%$ in 2009 and 2011, respectively (Table 2). Although conception rate increased steadily, the overall rate remained low (32.2\%). The current figures are lower than previously reported values of 71.8-82.2\% (Samsson, 2001), 46.7\% (Belachew, 2003), and 54.3 and $54.9 \%$ obtained respectively by Kouamo and Sawadogo (2012. However, the conception rates are within the range of
$22-45 \%$ reported by Tegegne (1989), Shiferaw et al. (2003) and Bekana et al. (2007) in tropical areas; and 0-67\% Worldwide by Yang and Honaramooz (2010). The differences in conception rate may be attributed to factors associated with lack of adequate facilities like modern microscopes and standby generator for the programme, timing of insemination, feeding management, efficiency of heat detection, early embryonic mortality caused by stress during transfers and presence of ovarian cyst which are all known to negatively affect fertility (Chebel et al., 2004).

Results showed that a higher conception rate was achieved when embryos were transplanted at the midthird of the uterine horn (MI), compared to Lower third (L) and Upper third (U) (Table 3). This is in agreement with Duygu and Köker (2011), who reported that the mid-uterine horn gave better results, especially with fresh embryos.

Table 2. Conception rates following embryo transfer over a five year period at Namandala Farm, Kitale - Kenya

\begin{tabular}{lccc}
\hline Year & Number of animals & Conception rate $(\%)$ & CH-square \\
\hline 2007 & 32 & 25.00 & $8.000^{* * *}$ \\
2009 & 64 & 34.38 & $6.25^{* *}$ \\
2011 & 19 & 36.84 & $1.3167 \mathrm{NS}$ \\
Overall & 115 & 32.17 & $14.617^{* * *}$ \\
\hline
\end{tabular}

Key: ***,**, $*$ significant at $1 ; 5$ and $10 \%$, respectivly

Table 3. Conception rates in relation to deposit site

\begin{tabular}{lcc}
\hline Site on uterine horn & Number of animals & Conception rate (\%) \\
\hline Lower third & 26 & 26.92 \\
Mid third & 43 & 48.84 \\
Upper third & 44 & 20.93 \\
\hline
\end{tabular}


The recipients used during the exercise were either on day 7 or day 8 post-estrus. Results showed that stage of reception had an influence on conception. Recipients on day 8 had a higher conception rate than those on day 7 (Table 4).

Regression analysis showed that deposit site significantly influenced the conception rate, with the mid uterine horn (ds-mi) yielding a significantly higher success rate at $(\mathrm{P}<0.05)$ than the upper (ds-u) and lower uterine horn (ds-l). These findings are in agreement with those of Chebel et al. (2008). This also concurs with those reported by Sirard et al. (2006), and Terawaki and Asada (2002). The conception rate $(\mathrm{CR})$ in the mid third was higher than in the upper third and the lower third of the uterine horn. This is in agreement with observation of Chebel $e t$ al. (2004) and Steel and Hasler (2004), who showed that CR in deep transfers is higher than in the superficial transfers. The embryo stages and the stage of the recipient after estrus had no influence on CR compared to the deposit site (Tables 5 and 6). It is, therefore, important to

Table 4. Conception rate in relation to stage of recipient after estrus cycle at Agricultural Development Corporation (ADC) Namandala Farm in Kenya

\begin{tabular}{lcc}
\hline Stage of recipient after estrus & \multicolumn{2}{c}{ Recipient animals that conceived $(\%)$} \\
\cline { 2 - 3 } & $\begin{array}{c}\text { No pregnancy } \\
(\%)(\mathrm{n}=78)\end{array}$ & $\begin{array}{c}\text { With pregnancy } \\
(\%)(\mathrm{n}=37)\end{array}$ \\
\hline 7 days after estrous $(\mathrm{n}=39)$ & 76.9 & 23.1 \\
8 days after estrous $(\mathrm{n}=76)$ & 63.2 & 36.8 \\
Total $(\mathrm{n}=115)$ & 67.8 & 32.2 \\
\hline
\end{tabular}

Table 5. Logit regression analysis on factors influencing conception rates (Dependent variable 1 = positive; 0 = negative)

\begin{tabular}{lllll}
\hline Variable & Coef. & Std. Err. & Z & P Z \\
\hline Embryo blastocyst (es_b) & 0.506431 & 0.797393 & 0.64 & 0.525 \\
Embryo stage early blastocyst es_eb & 0.107933 & 0.664189 & 0.16 & 0.871 \\
Embryo stage Morula (es_m) & 0.985359 & 0.641127 & 1.54 & 0.124 \\
Deposit site lower(ds_1) & 0.239134 & 0.598414 & 0.4 & 0.689 \\
Deposit site mid (ds_mi) & 1.26206 & 0.502049 & 2.51 & 0.012 \\
Stage of recipient after estrus (sr) & 0.742708 & 0.492882 & 1.51 & 0.132 \\
_cons & -7.53411 & 3.895576 & -1.93 & 0.053 \\
& & & & \\
Number of obs & 115 & & & \\
LR chi ${ }^{2}$ (6) & $14.05 * *$ & & & \\
Prob $>$ chi & & & & \\
Log likelihood & 0.0291 & & & \\
Pseudo R2 & -65.214998 & & & \\
\hline
\end{tabular}


Table 6. Marginal effects of Logit regression analysis on factors influencing conception rates for dairy herd

\begin{tabular}{llllll}
\hline Variable & dy/dx & Std.Err. & z & P z & X \\
\hline Embryo blastocyst (es_b) & 0.1136928 & 0.18838 & 0.6 & 0.546 & 0.113043 \\
Embryo stage early blastocyst es_eb & 0.0228393 & 0.14152 & 0.16 & 0.872 & 0.330435 \\
Embryo stage Morula (es_m) & 0.2140608 & 0.14061 & 1.52 & 0.128 & 0.373913 \\
Deposit site lower (ds_1) & 0.051493 & 0.13166 & 0.39 & 0.696 & 0.226087 \\
Deposit site mid (ds_mi) & $0.2739546^{* *}$ & 0.10758 & 2.55 & 0.011 & 0.382609 \\
Stage of recipient after estrus (sr) & 0.156048 & 0.10291 & 1.52 & 0.129 & 7.66087 \\
\hline
\end{tabular}

emphasize on the deposit site for better results.

The stages of development of the embryo had effects on the CR (Tables 5 and 6). However, the mid-deposit site (DS) had a significant effect on the CR $\left(\chi^{2}=0.2795 ; \mathrm{p}<0.05\right)$. The $\mathrm{CR}$ achieved from transfers done at the mid-third of the uterine horn, was higher than those deposited at the lower and upper third of the uterine horn. This may be attributed to the fact that the uterus was not be ready for implantation in regard to the lower deposit. The upper third also has lower conception rate because there is a lot of manipulation when trying to deposit the embryo which might lead to injuries or stress to the cow and thus reduce the conception.

The Conception Rate (CR) was deeply influenced by the deposit site (Table 5). However, the number of unsuccessful pregnancies exceeded the number of successful pregnancy. This may be attributed to poor facilities available for the programme, especially the frequent loss of power. The CR was also deeply influenced by the depth of the transfer. The CR in the mid-third was higher than in the upper third and the lower third of the uterine horn. This is in agreement with observation of Chebel et al. (2004) and Steel and Hasler (2004), who showed that
$\mathrm{CR}$ in deep transfers was higher than in the superficial transfers.

\section{Conclusion}

The key influencing factors on the success rate of embryo transfer at ADC Namandala in Kenya are site of placement and days after estrus of the recipient. However, the deposit site significantly affects the conception rate, likely due to the readiness of the uterus for the embryo implantation and manipulation of the uterine horn during the deposits.

Stage of the embryo has no significant influence on conception rate; however, more research needs to be done to ascertain this.

\section{Acknowledgement}

The authors thank the staff of Agricultural Development Corporation (ADC) Namandala for data collection and Japheth Wanyama of Kenya Agricultural Research Institute (KARI) who analysed the data.

\section{References}

Bekana, M., Odensvik, K. and Kindahl, H. 2007. Prostaglandin $\mathrm{F}_{2}$ a metabolite 
and progesterone profile in post-partum cows with retained foetal membranes. Acta Veterinaria Scandinavia 37: 171-185.

Belachew, T. 2003. Reproductive performance and Major Related Fertility Problems in Female cattle at Abernosa Ranch in Central Rift Valley. DVM thesis, Addis Ababa University, Faculty of Veterinary Medicine, Debre Zeit, Ethiopia.

Chebel, R.C., Santos, J.E.P., Reynolds, J.P., Cerri, R.L.A., Juchem, S.O. and Overton, M. 2004. Factors affecting conception rate after artificial insemination and embryonic loss in lactating dairy cows. Anim. Reprod. Sci. 84:239-255.

Chebel, R. C.,Dem étrio, D.G.B. and Metzger, J. 2008. Factors affecting success of embryo collection and transfer in large dairy herds. Theriogenology 69:98-106.

Duygu, I. and Köker, A. 2011. The effect of estrus synchronization on the reproductive characteristics of Turkish Saanen goats and growth characteristics of kids under extensive conditions. African Journal of Agricultural Research 6(26): 57155719. http://www.academicjournals. org/.../pdf2011/.../Incea\%

Ehui, S.K. and Shapiro, B.I. 2009. Research and Technology transfer for livestock development. Journal of Animal Science 87:801-812.

Glenn, S. 2004. Embryo transfer in cattle. Oklahoma State University, Division of Agriculture, USA.

Hasler, J.F. 2012. Applied reproductive strategies in cattle. Bio niche Animal Health, Inc. NE 1335 Terre View Dr. Pullman, WA 99163.

Kabubo-Mariara，J. 2009. Global warming and livestock husbandry in
Kenya: Impacts and adaptations. Ecological Economics 68: 1915 1924.

Kios, D., Estè, V.M. and Carina, V. 2011. Application of DNA markers in parentage verification of Boran cattle in Kenya: Journal of Animal Science 83:2271-2279.

Kouamo, J. and Sawadogo, G.J. 2012. Synchronization rate and factors affecting pregnancy rate after synchronization of estrus cycle and insemination of Gobra zebu (Bos indicus) in traditional area in Senegal. Livestock Research for Rural Development.

Lamb, C. 2012. Factors affecting pregnancy rates in an IVF embryo transfer program. Joint Proceedings of the AETA and the CETA. pp. 3136.

Mapletoft, R.J., Colazo, M., Martinez, M. and Kastelic, J.P. 2012. Application of fixed time AI in beef management programs in Canada. In: International Symposium for Animal Production, 6 . 2012, Cordoba, Argentina. Proceedings. Cordoba. pp. 81-96.

Muchemi, J. 2011. New embryo transfer technology to boost dairy farmers' fortune, Sunday Nation, Kenya. Aug. pp. 26-27.

Mwangi, D.M. and Omore, A. 2004. The livestock revolution - A view on implication for Africa. In: Responding to the livestock revolution. British Society of Animal Science 33:51 - 66.

Peterson, A.J. and Lee, R.S. 2003. Improving successful pregnancies after embryo transfer. Theriogenology 59:687-97.

Rege, J.E.O. 2009. Biotechnology options for improving livestock production in developing countries with special reference to Sub-Saharan Africa. 
Society of Animal Science, oocyte to embryo quality. Loskopdam, Pretoria, Octobe http:// Theriogenology 65:126-136.

www.fao.org/wairdocs/ilri/x5473b/ Steel, R. and Hasler, J. F. 2004. Pregnancy x5473b05.htm

Robertson, I. and Nelson, R.E. 1998. Certification and Identification of the embryo ( $3^{\text {rd }}$ Edition), International Embryo Transfer Society. Savoy, USA. pp 103-116.

Samsson, A. 2001 Assessment of the reproductive performance of artificially inseminated cattle in and around Addis Ababa, DVM thesis, Addis Ababa University, Faculty of Veterinary Medicine, Debre Zeit, Ethiopia.

Shiferaw, Y., Tenhagen, B.A., Bekana, M. and Kassa, T. 2003. Reproductive performance of cross breed dairy cows in different production systems in the central Highlands of Ethiopia. Tropical Animal Health and Production 35:551-61.

Sirard, M.A., Richard, F., Blodin, P. and Robert, C. 2006. Contribution of the rates resulting from transfer of fresh and frozen Holstein and Jersey embryos. Reproduction, Fertility and Development 16:182-183 (Abstract).

Tegegne, A. 1989. Reproductive development and function in zebu and crossbred cattle in Ethiopia. PhD Thesis. James Cook University, Australia.

Terawaki, Y. and Asada, Y. 2002. Relationships between distribution of number of transferable embryos and inbreeding coefficient in a MOET dairy cattle population. AsianAustralia. Journal for Animal Science. 15(12):1686-1689.

Yang, R.C. and Honaramooz. C. 2010. Effects of medium and hypothermic temperatures on preservation of isolated porcine testis cells. Reproduction, Fertility and Development 22:523-532. 